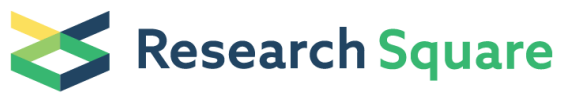 \\ Preprints are preliminary reports that have not undergone peer review. \\ They should not be considered conclusive, used to inform clinical practice, or referenced by the media as validated information.
}

\section{High endemicity of Clonorchis sinensis infection in Binyang County, southern China}

Junling Sun

Chinese Center for Disease Control and Prevention

Hualei Xin ( $\nabla$ xinhualei1987@126.com )

Chinese Center for Disease Control and Prevention https://orcid.org/0000-0001-8944-3980

Zhihua Jiang

Guangxi Center for Disease Control and Prevention

Menbao Qian

National Institute of Parasitic Diseases, Chinese

Kaixia Duan

Yunnan Institute of Parasitic Diseases

Yingdan Chen

National Institute of Parasitic Diseases, Chinese

Shizhu Li

National Institute of Parasitic Diseases, Chinese

Wei Li

Binyang Center for Disease Control and Prevention

Shiyong Huang

Binyang Center for Disease Control and Prevention

Xiaoqin Gan

Binyang Center for Disease Control and Prevention

Yichao Yang

Guangxi Center for Disease Control and Prevention

Zhongjie Li

Chinese Center for Disease Control and Prevention

\section{Research}

Keywords: Clonorchiasis, Clonorchis sinensis, Infection intensity, China, Binyang County, Raw fish

Posted Date: January 6th, 2020

DOI: https://doi.org/10.21203/rs.2.20102/v1

License: (9) (1) This work is licensed under a Creative Commons Attribution 4.0 International License. Read Full License

Version of Record: A version of this preprint was published at PLOS Neglected Tropical Diseases on August 10th, 2020. See the published version at https://doi.org/10.1371/journal.pntd.0008540. 


\section{Abstract}

Background

High-intensity clonorchiasis infection is associated with serious outcomes, even cancers. Understanding the infection intensity of Clonorchis sinensis and the impact factors in local endemic regions would facilitate effective control measures.

Methods

In a county located in a highly endemic area in Guangxi Province, P. R. China, local residents were randomly enrolled in the study; helminth egg examinations were performed with the Kato-Katz method, and the intensity of infection was identified as mild, moderate or heavy. Knowledge, attitudes, and high-risk behaviours were investigated among those infected with Clonorchis sinensis.

Results

A total of 2521 local residents participated in this study, and the Clonorchis sinensis infection proportion was $28.9 \%$ (728 persons). Among the infected persons, the percentages of mild, moderate and heavy infections were $66.2 \%, 28.4 \%$ and $5.4 \%$, respectively. Males experienced a higher proportion of moderate and heavy infections $(37.5 \%)$ than females $(18.1 \%)(p<0.05)$. The highest infection proportion among the different levels of infection intensity was identified among persons aged $30-59$ years (15.7\% for moderate and heavy infections). Among the 509 persons who reported eating raw fish, 302 persons ( $59.3 \%$ ) had eaten raw fresh fish for more than 10 years, and 131 (25.7\%) persons ate raw fish $\geq 12$ times a year. Multivariate logistic regression revealed that eating raw fish $12-50$ times in the last year (adjusted odds ratio $[\mathrm{aOR}]=1.74,95 \% \mathrm{Cl}: 1.09-2.80$ ) and eating raw fish $>50$ times in the last year $(\mathrm{aOR}=2.89,95 \% \mathrm{Cl}$ : $1.20-$ 7.50) were risk factors of higher infection intensity (moderate and heavy).

Conclusions

The overall infection proportion was high in the study area, with a large group of residents experiencing high-intensity infections. Intervention strategies should be implemented with people with a high frequency of raw fish consumption to reduce the probability of severe consequences.

\section{Background}

Clonorchis sinensis, the oriental liver fluke, is an important fish-borne zoonosis. Adult Clonorchis sinensis, which are located in the livers of various mammals, including humans, produce eggs that are passed into the intestine. Most of the parasites live in bile ducts, gallbladder and liver parenchyma, causing liver and biliary diseases. Human beings become infected by ingesting raw or undercooked fish that contain the metacercariae of liver flukes [1-5].

Globally, the distribution range of Clonorchis sinensis mainly consists of two epidemic zones. The first zone includes southeastern China and the northern area of Vietnam, and the second zone covers northeastern China, the Republic of Korea, part of Russia and probably the Democratic People's Republic of Korea [5]. The conservative estimate of the population infected with Clonorchis sinensis reached 15 million in 2004 globally, with over $85 \%$ of the estimated population in China [5]. There are two major endemic regions in China, i.e., southeastern China, including Guangdong and Guangxi with prevalence rates of $16.42 \%$ and $9.76 \%$, respectively, and northeastern China, including Heilongjiang, Jilin and Liaoning with prevalence rates of $16.42 \%, 9.76 \%, 4.73 \%, 2.90 \%$ and $0.80 \%$, respectively, between 2002-2004 [6-9]. According to the results of three large-scale surveys of clonorchiasis carried out in mainland China, the prevalence of clonorchiasis increased from $0.37 \%$ between 1988 and 1992 to $0.58 \%$ between 2002 and 2004, which indicated that the population infected with clonorchiasis increased from 4.70 million to 12.49 million people [8-10].

Symptoms caused by clonorchiasis are associated with worm burden $[1,6,11]$. Hence, patients with low infection intensity are often asymptomatic or show only mild symptoms, whereas patients with high infection intensity often show unspecific symptoms, such as asthenia, nausea, indigestion, headache or abdominal pain, especially in the right upper quadrant $[6,12]$. In addition, developmental retardation has been reported in children with heavy infection intensity. These children often present with inappetence, diarrhoea, malnutrition, anaemia and hepatomegaly [13]. Cholelithiasis is one of the most frequent complications of such infection. Previous studies discovered that a high worm burden and narrowing of the bile ducts, which might result from the accumulation of worms, cause obstruction, sequential bile stagnation, and bile pigment deposition, which may give rise to the formation of stones in bile ducts with eggs or dead worms as nuclei [14-17]. Additionally, Clonorchis sinensis infection is now widely acknowledged to be associated with cholangiocarcinoma, i.e., bile duct cancer $[18,19]$. As evidence accrued, Clonorchis sinensis and Opisthorchis viverrini were classified in 2009 as definite carcinogens (group 1) by the International Agency for Research on Cancer [18, 19]. Systematic reviews and meta-analyses revealed pooled odds ratios (ORs) for Clonorchis sinensis infection and cholangiocarcinoma ranging between 4.5 and 6.1 [5,20,21]. Additionally, in a study focusing on the relationship between liver flukes and cholangiocarcinoma, the higher the infection intensity was, the higher the (OR) [22].

In this study, we aim to explore the epidemiological characteristics of clonorchiasis in local endemic areas, with an emphasis on understanding the distribution of infection intensity and risk factors of high intensity, which can contribute to the effective and sustainable development of intervention measures.

\section{Methods \\ Study site}


The study was carried out in Binyang County, Nanning City, Guangxi Autonomous Region, P.R. China (Fig. 1). According to previous studies, clonorchiasis in Guangxi is hyper-epidemic in the Pearl River Basin [23], where Binyang County is located, but a clear epidemiological picture of clonorchiasis in this area is not available. Binyang County has 16 towns and a population of approximately 1.1 million. The annual discretionary income per capita reached 33095 CNY for urban citizens and 14038 CNY for rural citizens in 2018.

\section{Study design and data collection}

Among all 16 towns of Binyang County, 7 towns were identified as the survey areas by using a random sampling method, and two villages from each town were further selected. In each survey village, 200 residents were randomly enrolled in the survey. The same questionnaire was used to collect the demographic information, including age, sex, education and occupation, of all enrolled study participants. Furthermore, one stool sample was collected from each participant. Experienced and trained public health staff prepared three Kato-Katz thick smears for each sample and examined them for eggs under a light microscope [24, 25]. Clonorchis sinensis infection was defined based on the identification of Clonorchis sinensis eggs in stool specimens [24, 25].

After the faecal examination, participants who were confirmed to be infected with Clonorchis sinensis rather than any other helminth infection were asked to complete the structured questionnaire with trained investigators. The questionnaire contained four parts: demographic characteristics, previous illness history, knowledge and attitude towards clonorchiasis, and risk behaviours related to Clonorchis sinensis infection. In the demographic part, sex, age, occupation and education were recorded. Four questions related to knowledge and attitudes (e.g., "Do you know the transmission route" and "Do you know the most serious consequences caused by clonorchiasis?") were asked. Other questions about raw fish consumption, such as the duration, frequency, quantity and location of raw fish consumption, were recorded in the risk behaviours part.

\section{Data analysis}

The data were double-entered and cross-checked in EpiDate 3.1 software (http://www.epidata.dk/). Analysis was performed in R Studio software (Version 1.0 .153 , Inc.). The overall infection proportion was computed by dividing the number of infected persons by the total number of survey participants, and the proportion was standardized by using different age groups of the local population (in 2017). The population data used to calculate the standardized proportion were obtained from the Statistics Bureau of Nanning District. The number of eggs per gram of faeces (EPG) was calculated by multiplying the egg count of every smear by 24 and then computing the average of three smears. The intensity of infection was categorized as mild infection (EPG 1-999), moderate infection (EPG 1000-9999) or heavy infection (EPG $\geq 10000$ ) [20].

The overall proportions of mild, moderate and heavy infections were calculated by dividing the number of mild, moderate and heavy infections by the total number of infections. Moreover, the infection proportion and the proportions of the three types of infection intensity (mild infection, moderate infection and heavy infection) for different population groups (by sex, age, occupation and education level) were calculated and compared. Age was transformed into five categories $(15,15-29,30-44,45-59$, and 59 years).

To understand raw fish consumption behaviour in the study subjects, we calculated and compared the duration ( $0-5$ years, 6-10 years and $>10$ years), frequency ( $0-11$ times a year, $12-50$ times a year and $>50$ times a year) and quantity ( $0-9$ slices, $10-19$ slices and $\geq 20$ slices per serving of raw fish) of raw fish consumption for the overall population and different population groups; the use of anti-parasitics after eating raw fish; and the main location of raw fish consumption. Univariate and multivariate logistic regression models were used to explore the relationship between raw fish consumption behaviour and highintensity infection (moderate and heavy infections).

Pearson's $\chi^{2}$ test was applied to assess the association between the categorical variables. Statistical significance was determined at a p-value of 0.05 .

This study was approved by the ethics committees of the Chinese Center for Disease Control and Prevention (Approval Notice no: 201617). The objectives, procedures and potential risks were orally explained to all participants. A written consent form was also obtained from each participant with his or her own signature or the signature of a proxy.

\section{Results}

\section{Basic characteristics of the study subjects}

A total of 2521 subjects participated in this study, of whom 728 were infected with Clonorchis sinensis. The overall infection proportion was $28.9 \%$, and the standardized infection proportion was $27.1 \%$. Of the 728 residents who were infected with Clonorchis sinensis, 590 ( $81.0 \%)$ were male. The age of the infected persons ranged from 3 to 88 years, with an average age of 50 years and a median age of 51 years (interquartile range: 41-60). Most of the infected persons $(97.8 \%)$ were adults aged over 15 years old. Additionally, 2 (0.3\%) were co-infected with trichurids (Table 1$)$.

Table 1. Demographic and infection intensity characteristics of the screened subjects in Binyang county. 


\begin{tabular}{|c|c|c|c|c|c|}
\hline \multirow[t]{2}{*}{ Feature } & \multirow[t]{2}{*}{ Screened subjects } & \multirow[t]{2}{*}{ No. of infection (\%) } & \multicolumn{3}{|c|}{ No. of infection intensity (\%) } \\
\hline & & & Mild & Moderate & Heavy \\
\hline Overall & 2521 & $728(28.9)$ & $482(66.2)$ & $207(28.4)$ & $39(5.4)$ \\
\hline \multicolumn{6}{|l|}{ Co-infection } \\
\hline With trichurid & 728 & $2(0.3)$ & & & \\
\hline \multicolumn{6}{|l|}{ Gender } \\
\hline Male & 1353 & $590(43.6) *$ & $369(62.5))^{\#}$ & 184(31.2) & $37(6.3)$ \\
\hline Female & 1168 & 138(11.8) & 113(81.9) & $23(16.7)$ & $2(1.4)$ \\
\hline \multicolumn{6}{|l|}{ Age group } \\
\hline$<15$ & 625 & $14(2.2) *$ & 13(92.9) & $1(7.1)$ & $0(0.0)$ \\
\hline $15-29$ & 158 & $34(21.5)$ & $23(67.6)$ & $11(32.4)$ & $0(0.0)$ \\
\hline $30-44$ & 464 & $189(40.7)$ & $125(66.1)$ & $56(29.6)$ & $8(4.2)$ \\
\hline $45-59$ & 655 & $296(45.2)$ & $184(62.2)$ & $90(30.4)$ & $22(7.4)$ \\
\hline$>59$ & 565 & 192(34.0) & $134(69.8)$ & $49(25.5)$ & $9(4.7)$ \\
\hline \multicolumn{6}{|l|}{ Occupation } \\
\hline Student/child & 621 & $13(2.1) *$ & 12(92.3) & $1(7.7)$ & $0(0.0)$ \\
\hline Farmer & 1651 & $628(38.0)$ & $412(65.6)$ & 182(29.0) & $34(5.4)$ \\
\hline Others & 249 & $87(34.9)$ & $58(66.7)$ & $24(27.6)$ & $5(5.7)$ \\
\hline \multicolumn{6}{|l|}{ Education } \\
\hline Illiterate and preschool & 29 & $6(20.7)$ * & $6(100.0)$ & $0(0.0)$ & $0(0.0)$ \\
\hline Primary school & 527 & 175(33.2) & 118(67.4) & $46(26.3)$ & $11(6.3)$ \\
\hline Junior high school & 1050 & $434(41.3)$ & $274(63.1)$ & 136(31.3) & $24(5.5)$ \\
\hline Senior high school & 128 & $56(43.8)$ & $38(67.9)$ & $15(26.8)$ & $3(5.4)$ \\
\hline University & 68 & $31(45.6)$ & $22(71.0)$ & $8(25.8)$ & $1(3.2)$ \\
\hline
\end{tabular}

\section{Infection intensity}

Among the 728 persons infected with Clonorchis sinensis, the geometric mean EPG was 381, and the percentages of mild, moderate and heavy infections were $66.2 \%, 28.4 \%$ and $5.4 \%$, respectively. A significant difference in infection intensity was identified between males and females $\left(\chi^{2}=19.466, p<0.01\right)$. Males (37.5\%) developed a higher percentage of moderate and heavy infections than females $(18.1 \%)(p<0.01)$. The percentage of moderate and heavy infections increased from $7.1 \%$ in $<15$-year-olds to $37.8 \%$ in 45 -59-year-olds and then decreased in $>59$-year-olds (33.3\%) (Table 1$)$.

The proportion of infected males was higher than the proportion of infected females in all age groups, except for children under 15 years old (Fig. $2 a$ ). In all age groups except for children under 15 years old, the proportion of mild infection was higher than the proportion of moderate and heavy infections both in males and females (Fig. $2 b$ and c). The infection proportions for all three types of infection intensity increased with age in those aged from < 15 years old to 30-59 years old and then began to decrease in those $>59$ years old (Fig. 2).

\section{Risk behaviour among different groups}

Among the 728 infected persons, 538 (73.9\%) participated in the questionnaire, of whom 509 (94.6\%) reported eating raw fish. Males (96.2\%) had a higher rate of raw fish consumption than females $(86.8 \%)\left(\chi^{2}=13.055, p<0.01\right)$. Among the 509 persons who reported eating raw fish, $302(59.3 \%)$ had eaten raw fish for $>10$ years, 131 (25.7\%) ate raw fish $\geq 12$ times a year, and 291 (57.2\%) ate $\geq 20$ slices every time they ate raw fish. Four hundred ninety-four ( $97.1 \%$ ) did not take anti-parasitics after eating raw fish, and 432 (84.9\%) reported eating raw fish at home (Table 2). 
Table 2

Raw fish consumption behaviour of different groups of infected persons in Binyang county

\begin{tabular}{|c|c|c|c|c|c|c|c|c|c|c|}
\hline \multirow[t]{2}{*}{ Feature } & \multirow[t]{2}{*}{$\begin{array}{l}\text { Eat raw } \\
\text { fish }\end{array}$} & \multicolumn{3}{|c|}{$\begin{array}{l}\text { Years of raw fish consumption } \\
(n, \%)\end{array}$} & \multicolumn{3}{|c|}{$\begin{array}{l}\text { Frequency of raw fish } \\
\text { consumption } \\
\text { (times in the last year) }(n, \%)\end{array}$} & \multicolumn{3}{|c|}{$\begin{array}{l}\text { Quantity of raw fish consumption } \\
\text { (slices per serving) }(n, \%)\end{array}$} \\
\hline & & $\leq 5$ & $6-10$ & $>10$ & $\leq 11$ & $12-50$ & $>50$ & $\leq 9$ & $10-19$ & $\geq 20$ \\
\hline $\begin{array}{l}\text { Overall }(\mathrm{N}= \\
538)\end{array}$ & $509(94.6)$ & 118(23.2) & $89(17.5)$ & 302(59.3) & $378(74.3)$ & 107(21.0) & $24(4.7)$ & $95(18.7)$ & $123(24.2)$ & 291(57.2) \\
\hline \multicolumn{11}{|l|}{ Gender } \\
\hline $\begin{array}{l}\text { Male }(\mathrm{N}= \\
447)\end{array}$ & $430(96.2)$ & $91(21.2)$ & $69(16.0)$ & $270(62.8)$ & $303(70.5)$ & $103(24.0)$ & $24(5.6)$ & $51(11.9)$ & $108(25.1)$ & $271(63.0)$ \\
\hline $\begin{array}{l}\text { Female }(\mathrm{N}= \\
91)\end{array}$ & $79(86.8)$ & $27(34.2)$ & $20(25.3)$ & $32(40.5)$ & $75(94.9)$ & $4(5.1)$ & $0(0.0)$ & $44(55.7)$ & $15(19.0)$ & $20(25.3)$ \\
\hline \multicolumn{11}{|l|}{ Age group } \\
\hline $\begin{array}{l}0-29(\mathrm{~N}= \\
24)\end{array}$ & 19(79.2) & $14(73.7)$ & $4(21.1)$ & $1(5.3)$ & 17(89.5) & 2(10.5) & $0(0.0)$ & $6(31.6)$ & $8(42.1)$ & $5(26.3)$ \\
\hline $\begin{array}{l}30-44(N= \\
140)\end{array}$ & 136(97.1) & $45(33.1)$ & $36(26.5)$ & $55(40.4)$ & 108(79.4) & $21(15.4)$ & $7(5.1)$ & $25(18.4)$ & $41(30.1)$ & $70(51.5)$ \\
\hline $\begin{array}{l}45-59(N= \\
227)\end{array}$ & $218(96.0)$ & $35(16.1)$ & $31(14.2)$ & 152(69.7) & $150(68.8)$ & $54(24.8)$ & $14(6.4)$ & $37(17.0)$ & $49(22.5)$ & $132(60.6)$ \\
\hline$>60(\mathrm{~N}=147)$ & $136(92.5)$ & $24(17.6)$ & 18(13.2) & $94(69.1)$ & 103(75.7) & $30(22.1)$ & $3(2.2)$ & 27(19.9) & 25(18.4) & $84(61.8)$ \\
\hline \multicolumn{11}{|l|}{ Occupation } \\
\hline $\begin{array}{l}\text { Farmer }(\mathrm{N}= \\
461)\end{array}$ & $439(95.2)$ & $87(19.8)$ & 76(17.3) & $276(62.9)$ & $322(73.3)$ & $96(21.9)$ & $21(4.8)$ & $78(17.8)$ & $100(22.8)$ & 261(59.5) \\
\hline $\begin{array}{l}\text { Others }(\mathrm{N}= \\
77)\end{array}$ & $70(90.9)$ & $31(44.3)$ & $13(18.6)$ & $26(37.1)$ & $56(80.0)$ & $11(15.7)$ & $3(4.3)$ & $17(24.3)$ & $23(32.9)$ & $30(42.9)$ \\
\hline \multicolumn{11}{|l|}{ Education } \\
\hline $\begin{array}{l}\text { Primary } \\
\text { school or } \\
\text { below }(\mathrm{N}= \\
197)\end{array}$ & $180(91.4)$ & $34(18.9)$ & $30(16.7)$ & $116(64.4)$ & $128(71.1)$ & $43(23.9)$ & $9(5.0)$ & $40(22.2)$ & $32(17.8)$ & $108(60.0)$ \\
\hline $\begin{array}{l}\text { Junior high } \\
\text { school }(\mathrm{N}= \\
266)\end{array}$ & 257(96.6) & $56(21.8)$ & $48(18.7)$ & $153(59.5)$ & 192(74.7) & $53(20.6)$ & $12(4.7)$ & $42(16.3)$ & $68(26.5)$ & $147(57.2)$ \\
\hline $\begin{array}{l}\text { Senior high } \\
\text { school or } \\
\text { above }(\mathrm{N}= \\
75)\end{array}$ & 72(96.0) & $28(38.9)$ & 11(15.3) & $33(45.8)$ & $58(80.6)$ & $11(15.3)$ & $3(4.2)$ & $13(18.1)$ & 23(31.9) & $36(50.0)$ \\
\hline \multicolumn{11}{|l|}{$\begin{array}{l}\text { Previous } \\
\text { diagnosis } \\
\text { with } \\
\text { clonorchiasis }\end{array}$} \\
\hline Yes $(N=57)$ & $57(100.0)$ & $5(8.8)$ & $7(12.3)$ & $45(78.9)$ & $35(61.4)$ & $17(29.8)$ & $5(8.8)$ & $7(12.3)$ & $18(31.6)$ & $32(56.1)$ \\
\hline No $(N=481)$ & $452(94.0)$ & $113(25.0)$ & $82(18.1)$ & $257(56.9)$ & $343(75.9)$ & $90(19.9)$ & 19(4.2) & $88(19.5)$ & $105(23.2)$ & $259(57.3)$ \\
\hline \multicolumn{11}{|l|}{$\begin{array}{l}\text { Previously } \\
\text { use of anti- } \\
\text { parasitic }\end{array}$} \\
\hline Yes $(N=50)$ & $50(100.0)$ & $4(8.0)$ & $7(14.0)$ & $39(78.0)$ & $30(60.0)$ & $15(30.0)$ & $5(10.0)$ & $5(10.0)$ & $16(32.0)$ & $29(58.0)$ \\
\hline No $(N=488)$ & $459(94.1)$ & $114(24.8)$ & $82(17.9)$ & $263(57.3)$ & $348(75.8)$ & $92(20.0)$ & $19(4.1)$ & $90(19.6)$ & 107(23.3) & $262(57.1)$ \\
\hline \multicolumn{11}{|l|}{$\begin{array}{l}\text { Knowledge } \\
\text { of the } \\
\text { transmission } \\
\text { route of } \\
\text { clonorchiasis }\end{array}$} \\
\hline Yes $(N=308)$ & $304(98.7)$ & $70(23.0)$ & $50(16.4)$ & $184(60.5)$ & $220(72.4)$ & $65(21.4)$ & $19(6.3)$ & $45(14.8)$ & $76(25.0)$ & $183(60.2)$ \\
\hline No $(N=230)$ & 205(89.1) & $48(23.4)$ & $39(19.0)$ & $118(57.6)$ & 158(77.1) & $42(20.5)$ & $5(2.4)$ & $50(24.4)$ & $47(22.9)$ & $108(52.7)$ \\
\hline
\end{tabular}




\begin{tabular}{|c|c|c|c|c|c|c|c|c|c|c|}
\hline \multirow[t]{2}{*}{ Feature } & \multirow[t]{2}{*}{$\begin{array}{l}\text { Eat raw } \\
\text { fish }\end{array}$} & \multicolumn{3}{|c|}{$\begin{array}{l}\text { Years of raw fish consumption } \\
(n, \%)\end{array}$} & \multicolumn{3}{|c|}{$\begin{array}{l}\text { Frequency of raw fish } \\
\text { consumption } \\
\text { (times in the last year) }(n, \%)\end{array}$} & \multicolumn{3}{|c|}{$\begin{array}{l}\text { Quantity of raw fish consumption } \\
\text { (slices per serving) }(n, \%)\end{array}$} \\
\hline & & $\leq 5$ & $6-10$ & $>10$ & $\leq 11$ & $12-50$ & $>50$ & $\leq 9$ & $10-19$ & $\geq 20$ \\
\hline \multicolumn{11}{|l|}{$\begin{array}{l}\text { Knowledge } \\
\text { of potential } \\
\text { to cause } \\
\text { cancer }\end{array}$} \\
\hline Yes $(N=57)$ & $55(96.5)$ & $12(21.8)$ & $5(9.1)$ & $38(69.1)$ & $39(70.9)$ & 15(27.3) & $1(1.8)$ & $9(16.4)$ & 13(23.6) & $33(60.0)$ \\
\hline No $(N=481)$ & $454(94.4)$ & 106(23.3) & $84(18.5)$ & $264(58.1)$ & $339(74.7)$ & $92(20.3)$ & $23(5.1)$ & 86(18.9) & $110(24.2)$ & $258(56.8)$ \\
\hline
\end{tabular}

Among the 509 persons who reported eating raw fish, higher percentages of males than females had eaten raw fish for $>10$ years $\left(62.8 \%\right.$ vs $40.5 \%$, $\chi^{2}=$ $13.735, p<0.01)$, ate raw fish $\geq 12$ times a year $\left(29.6 \%\right.$ vs $\left.5.1 \%, \chi^{2}=20.911, p<0.01\right)$ and ate $\geq 20$ slices every time they ate raw fish $\left(63.0 \%\right.$ vs $25.3 \%, \chi^{2}=$ $38.753, p<0.01)$. Additionally, a higher percentage of males $(17.2 \%)$ than females $(3.8 \%)$ reported eating raw fish at restaurants $\left(\chi^{2}=9.350, p<0.01\right)$. Higher percentages of persons who had been previously diagnosed with clonorchiasis than those who had not been previously diagnosed reported eating raw fish for $>10$ years $\left(78.9 \%\right.$ vs $\left.56.9 \%, \chi^{2}=10.235, p<0.01\right)$ and eating raw fish $\geq 12$ times a year $\left(38.6 \%\right.$ vs $\left.24.1 \%, \chi^{2}=5.554, p=0.018\right)$. Furthermore, higher percentages of those who had previously taken anti-parasitics than those who had not taken anti-parasitics reported having eaten raw fish for $>10$ years $\left(78.0 \%\right.$ vs $\left.57.3 \%, \chi^{2}=8.008, p<0.01\right)$ and eating raw fish $\geq 12$ times a year $\left(40.0 \%\right.$ vs $\left.24.1 \%, \chi^{2}=5.902, p=0.015\right)$. No significant differences in raw fish consumption behaviour were identified between those with different knowledge of clonorchiasis (knowledge of the transmission route of clonorchiasis and that it causes cancer) (Table 2).

\section{Risk factors of high infection intensity}

Among the 509 persons who reported eating raw fish, 195 (38.3\%) were classified as having moderate or heavy infection intensity. The univariate analysis revealed that the risk factors of moderate and heavy infection intensity included eating raw fish for $>10$ years $(\mathrm{crude}$ odds ratio $[\mathrm{cOR}]=1.94,95 \% \mathrm{Cl}=1.24 \sim$ 3.10), eating raw fish $12-50$ times a year $(\mathrm{cOR}=2.17,95 \% \mathrm{Cl}=1.40 \sim 3.36)$, eating raw fish $>50$ times a year $(\mathrm{cOR}=4.10,95 \% \mathrm{Cl}=1.75 \sim 10.35)$ and eating $\geq$ 20 slices of raw fish per serving ( $\mathrm{cOR}=2.39,95 \% \mathrm{Cl}=1.45 \sim 4.05)$. However, the multivariate logistic regression analysis showed that only two subgroups had higher risks of moderate and heavy infection intensity: those who ate raw fish 12-50 times a year (adjusted odds ratio [aOR] $=1.74,95 \% \mathrm{Cl}=1.09 \sim 2.80$ ) and those who ate raw fish $>50$ times a year $(\mathrm{aOR}=2.89,95 \% \mathrm{Cl}=1.20 \sim 7.50)($ Table 3$)$.

Table 3. Risk factors of high infection intensity (moderate and heavy infections) based on multivariate logistic regression. 
Features

Total Moderate or heavy intensity of infection ( $n$,

$\operatorname{cOR}^{*}(95 \% \mathrm{Cl})$

$\mathrm{aOR}^{* \star}(95 \% \mathrm{Cl})$

\%)

Years of raw fish consumption

$\begin{array}{lllll}0-5 & 118 & 34(28.8) & \text { Ref } & \text { Ref } \\ 6-10 & 89 & 28(31.5) & 1.13(0.62-2.06) & 0.95(0.50-1.76) \\ >10 & 302 & 133(44.0) & 1.94(1.24-3.10) & 1.21(0.71-2.07)\end{array}$

Frequency of raw fish consumption

0-11 times per year

$378 \quad 124(32.8)$

Ref

Ref

12-50 times per year

$107 \quad 55(51.4)$

$2.17(1.40-3.36)$

1.74(1.09-2.80) \#

$>50$ times per year

$24 \quad 16(66.7)$

$4.10(1.75-10.35) \quad 2.89(1.20-7.50)$ \#

Quantity of raw fish consumption

$\begin{array}{lllll}0-9 & 95 & 25(26.3) & \text { Ref } & \text { Ref } \\ 10-19 & 123 & 36(29.3) & 1.16(0.64-2.13) & 1.01(0.55-1.89) \\ \geq 20 & 291 & 134(46.0) & 2.39(1.45-4.05) & 1.66(0.94-2.99)\end{array}$

Location of raw fish consumption

Restaurant and others

\begin{tabular}{|c|c|c|c|}
\hline Home & 432 & 161(37.3) & $0.75(0.46-1.23)$ \\
\hline
\end{tabular}

Use of anti-parasitic after eating raw fish

$\begin{array}{lllll}\text { No } & 494 & 188(38.1) & \text { Ref } & \text { Ref } \\ \text { Occasionally } & 15 & 7(46.7) & 1.42(0.49-4.03) & 1.24(0.41-3.67)\end{array}$

Previous diagnosis with clonorchiasis before

$\begin{array}{lllll}\text { Yes } & 57 & 23(40.4) & \text { Ref } & \text { Ref } \\ \text { No } & 481 & 172(35.8) & 0.91(0.52-1.61) & 1.15(0.63-2.15)\end{array}$

Knowledge of the infection route of

clonorchiasis

\begin{tabular}{lllll} 
Yes & 308 & $127(41.2)$ & Ref & Ref \\
No & 230 & $71(30.9)$ & $0.72(0.49-1.03)$ & $0.75(0.50-1.12)$ \\
\hline Knowledge of the potential to cause cancer & & & Ref & Ref \\
\hline Yes & 57 & $23(40.4)$ & $0.92(0.52-1.65)$ & $1.07(0.58-2.00)$ \\
\hline No & 481 & $175(36.4)$ & \\
\hline$*$ cOR: crude odds ratio; & & & \\
\hline$* *$ aOR: adjusted odds ratio; & & & \\
\hline \# Statistical differences identified. & & & \\
\hline
\end{tabular}

\section{Discussion}

In this study, by analysing cross-sectional data from an endemic area in China, we found that the infection proportion of clonorchiasis was high and that a large proportion of infected persons had moderate and heavy intensity infections. People aged 30-59 years had a higher infection proportion and a higher percentage of moderate and heavy infections than those in the other age groups. Males experienced a higher percentage of moderate and heavy intensity infections than females, which might be attributed to the longer duration, higher frequency and greater quantity of their raw fish consumptions. Additionally, people who had been previously diagnosed with clonorchiasis or had previously taken anti-parasitics had longer durations and higher frequencies of raw fish consumptions, while no differences were identified among people with different knowledge of clonorchiasis. Furthermore, a high frequency of raw fish consumption was a risk factor for a high intensity of infection.

The distribution characteristics of infection intensity and infection proportion among the sexes and age groups that were identified in this study were mainly related to living customs, i.e., raw fish consumption. Raw fish are often consumed in social gathering or at restaurants, and offering raw fish to guests is deemed a hospitable gesture; males have more opportunities to participate in these practices [8, 26, 27]. Moreover, raw fish are often enjoyed with alcoholic beverages, which is more common among males than females, except for among children $[5,28]$. Furthermore, adult worms can survive in the body for 
decades. Consequently, adult males' exposure and, consequently, their worm load are higher, which leads to higher infection intensity and higher prevalence. The decline in the overall prevalence of infection and the three types of infection intensity in those older than 60 is probably due to early death caused by clonorchiasis-related complications $[5,15]$. Additionally, elderly individuals seek medical services more frequently due to clonorchiasis-related complications or unrelated diseases and then accept diagnosis and treatment [5].

At present, the management of clonorchiasis is focused on morbidity control with praziquantel [29]. In moderately endemic areas (prevalence rate: $20 \%-40 \%$ ) [30], such as the area where our study site is located, yearly administration of praziquantel under selective chemotherapy resulted in a substantial decrease in the prevalence and intensity of infection within 3 years [30]. However, the sustainability of long-term achievements is challenging, as re-infection cannot be avoided in chemotherapy, especially in older age groups $[24,28,31]$. Information, education and communication (IEC) is usually combined with chemotherapy to enhance sustainability [6,32]. However, according to our study, no significant difference in raw fish consumption behaviour was identified among people with different knowledge of clonorchiasis. Hence, other control measures should be implemented in endemic areas. Currently, in local endemic areas of China, particularly in village regions, toilets are built directly above or beside fish ponds, and unprocessed faeces can contaminate the water, which increases Clonorchis sinensis infection in snails and freshwater fish [33]. Sanitary toilets with a harmless processing design, which have been previously implemented in one epidemic area in China with promising effects [33], should be tried in other endemic areas. Moreover, residents in epidemic areas find it difficult to change their raw fish consumption habits. Therefore, more attention should be paid to the safety of freshwater fish. The infection rates and distribution of freshwater fish should be investigated in endemic areas, and infected ponds should be placed under surveillance. Additionally, metacercaria-tainted fish should be barred from markets [34]. Currently, the direct compression or artificial digestion of fish followed by detection under a microscope is used to examine Clonorchis sinensis metacercaria in freshwater fish, which is time consuming and labour-intensive and can allow Clonorchis sinensis to be easily confused with other parasites [34-36]. Meanwhile, PCR-based molecular biology techniques are expensive [34]; thus, rapid, convenient, inexpensive and accurate detection methods are urgently needed. Moreover, a notable avenue of vaccine research is the vaccination of the second intermediate host, i.e., freshwater fish, with feed probiotics. Indeed, an oral vaccine based on Bacillus subtilis expressing enolase is being tested in freshwater fish [6,37].

One limitation exists in this study. Among the 728 persons who were infected with Clonorchis sinensis, only 538 (73.9\%) participated in our questionnaire investigation. Therefore, the results might have been influenced. However, we compared the basic demographic information (sex and age) between these 538 subjects and the 190 non-participating persons, and no significant difference was identified. Thus, we believe this had a limited effect on the results.

Based on our results, the overall infection proportion and intensity of clonorchiasis were high at the study site, with males experiencing higher intensity of infection than females. People 30-59 years old had a higher burden of clonorchiasis than those in the other age groups. In addition, males showed a higher risk of raw fish consumption than females, and no difference in raw fish consumption behaviour was noted among people with different knowledge of clonorchiasis. A high frequency of raw fish consumption was associated with a high intensity of infection. More measures focused on contaminated faeces and intermediates, such as the reconstruction of toilets and the examination of freshwater fish, should be implemented along with chemotherapy and IEC in local endemic areas.

\section{List Of Abbreviations}

CNY: Chinese yuan; IEC: Information, Education and Communication; EPG: eggs per gram; OR: odds ratio; aOR: adjusted odds ratio; cOR: crude odds ratio

\section{Declarations}

\section{Ethics approval and consent to participate}

This study was approved by the ethics committees in Chinese Center for Disease Control and Prevention (Approval Notice no: 201617). The objectives, procedures and potential risks were orally explained and informed to all participants. A written consent form was also obtained from each participant with signature of him or his proxy.

\section{Consent for publication}

Not applicable

\section{Availability of data and materials}

Data supporting the conclusions of this article are included within the article. The datasets generated during and/or analysed during the present study are available from the corresponding author upon reasonable request.

\section{Competing interests}

The authors declare that they have no competing interests

\section{Funding}

This study was supported by the National Science and Technology Major Project (No: 2018ZX10713-001-006, 2018ZX10713-001-005, 2018ZX10101002-003002), Emergency Response Mechanism Operation Program, Chinese Center for Disease Control and Prevention (No: 131031001000015001). The funders had no role in study design, data collection and analysis, decision to publish, or preparation of the manuscript. 
Conceived and designed the experiments: JLS HLX ZJL YCY. Performed the experiments: JLS HLX ZJL YCY ZHJ. Analyzed the data: JLS HLX. Contributed reagents/ materials/ analysis tools: JLS HLX ZJL YCY ZHJ MBQ KXD YDC SZL. Wrote the paper: JLS HLX ZJL. All authors read and approved the final version of the manuscript.

\section{Acknowledgements}

We are indebted to the staff from The Center for Disease Control and Prevention of Binyang County in Guangxi province for their assistance in field surveys.

\section{References}

1. Lun ZR, Gasser RB, Lai DH, Li AX, Zhu XQ, Yu XB, et al. Clonorchiasis: a key foodborne zoonosis in China. Lancet Infect Dis. 2005;5:31-41.

2. Keiser J, Utzinger J. Emerging foodborne trematodiasis. Emerg Infect Dis. 2005;11:1507-14.

3. Sripa B, Kaewkes S, Intapan PM, Maleewong W, Brindley PJ. Food-borne trematodiases in Southeast Asia epidemiology, pathology, clinical manifestation and control. Adv Parasitol. 2010;72:305-50.

4. Kruithof R, Erard V. Food-borne trematodiases. Rev Med Suisse. 2017;13:1741-4.

5. Qian MB, Chen YD, Liang S, Yang GJ, Zhou XN. The global epidemiology of clonorchiasis and its relation with cholangiocarcinoma. Infect Dis Poverty. 2012;1:4

6. Qian MB, Utzinger J, Keiser J, Zhou XN. Clonorchiasis. Lancet. 2016;387:800-10.

7. Kim TS, Cho SH, Huh S, Kong Y, Sohn WM, Hwang SS, et al. A nationwide survey on the prevalence of intestinal parasitic infections in the Republic of Korea, 2004. Korean J Parasitol. 2009;47:37-47.

8. Fang YY, Chen YD, Li XM, Wu J, Zhang QM, Ruan CW. Current prevalence of Clonorchis sinensis infection in endemic areas of China. Zhongguo Ji Sheng Chong Xue Yu Ji Sheng Chong Bing Za Zhi. 2008;26:99-103, 9.

9. Technical Steering Panel for National Survey of Current Status of Major Human Parasitic Diseases. Report on the national survey of current status of major human parasitic diseases in China. Beijing, China: People's Medical Publishing House; 2008.

10. WHO. Control of foodborne trematode infections, WHO technical report series. Geneva, Swithzerland: World Health Organisation; 1995.

11. Kim JH, Choi MH, Bae YM, Oh JK, Lim MK, Hong ST. Correlation between discharged worms and fecal egg counts in human clonorchiasis. PLoS Negl Trop Dis. 2011;5:e1339.

12. Du HC, Liu ZZ, Wu LJ. Clinical analysis on 2840 cases of clonorchiasis (in Chinese). Zhongguo Shi Yong Yi Yao 2008;3:96.

13. Zhu SH, Zhong XS, Luo ZY. Clonorchiasis and developmental disorder in the children (dwarfism). Xin Yi Xue. 1983;14:71-2.

14. Hong ST, Fang Y. Clonorchis sinensis and clonorchiasis, an update. Parasitol Int. 2012;61:17-24.

15. Choi BI, Han JK, Hong ST, Lee KH. Clonorchiasis and cholangiocarcinoma: etiologic relationship and imaging diagnosis. Clin Microbiol Rev. 2004;17:54052.

16. Choi D, Lim JH, Lee KT, Lee JK, Choi SH, Heo JS, et al. Gallstones and Clonorchis sinensis infection: a hospital-based case-control study in Korea. J Gastroenterol Hepatol. 2008;23:e399-404.

17. Hou PC. The pathology of Clonorchis sinensis infestation of the liver. J Pathol Bacteriol. 1955;70:53-64.

18. Bouvard V, Baan R, Straif K, Grosse Y, Secretan B, El Ghissassi F, et al. A review of human carcinogens-part B: biological agents. Lancet Oncol. 2009;10:321-2.

19. IARC. IARC monographs on the evaluation of carcinogenic risks to humans. A review of human carcinogens part B: biological agents. Lyon, France: International Agency for Research on Cancer; 2011.

20. Furst T, Keiser J, Utzinger J. Global burden of human food-borne trematodiasis: a systematic review and meta-analysis. Lancet Infect Dis. 2012;12:210-21.

21. Shin HR, Oh JK, Lim MK, Shin A, Kong HJ, Jung KW, et al. Descriptive epidemiology of cholangiocarcinoma and clonorchiasis in Korea. J Korean Med Sci. 2010;25:1011-6.

22. Haswell-Elkins MR, Mairiang E, Mairiang P, Chaiyakum J, Chamadol N, Loapaiboon V, et al. Cross-sectional study of Opisthorchis viverrini infection and cholangiocarcinoma in communities within a high-risk area in northeast Thailand. Int J Cancer. 1994;59:505-9.

23. Jiang ZH, Yang YC, Wan XL, Li CH, Huang FM. Preliminary analysis of geographical and basin distribution characteristics of clonorchiasis sinensis in Guangxi. China Trop Med. 2015;15:1057-61.

24. Qian MB, Chen YD, Fang YY, Tan T, Zhu TJ, Zhou CH, et al. Epidemiological profile of Clonorchis sinensis infection in one community, Guangdong, People's Republic of China. Parasit Vectors. 2013;6:194.

25. Katz N, Chaves A, Pellegrino J. A simple device for quantitative stool thick-smear technique in Schistosomiasis mansoni. Rev Inst Med Trop Sao Paulo. 1972;14:397-400.

26. Phan VT, Ersboll AK, Do DT, Dalsgaard A. Raw-fish-eating behavior and fishborne zoonotic trematode infection in people of northern Vietnam. Foodborne Pathog Dis. 2011;8:255-60.

27. Nontasut P, Thong TV, Waikagul J, Anantaphruti MT, Fungladda W, Imamee N, et al. Social and behavioral factors associated with clonorchis infection in one commune located in the red river delta of Vietnam. Southeast Asian J Trop Med Public Health. 2003;34:269-73.

28. WHO. First WHO report on neglected tropical diseases: working to overcome the global impact of neglected tropical diseases. Geneva, Switzerland: World Health Organisation; 2010.

Page $9 / 11$ 
29. WHO. Sustaining the drive to overcome the global impact of neglected tropical diseases: second WHO report on neglected tropical diseases. Geneva, Switzerland: World Health Organisation; 2013.

30. Choi MH, Park SK, Li Z, Ji Z, Yu G, Feng Z, et al. Effect of control strategies on prevalence, incidence and re-infection of clonorchiasis in endemic areas of China. PLoS Negl Trop Dis. 2010;4:e601.

31. Ziegler AD, Andrews RH, Grundy-Warr C, Sithithaworn P, Petney TN. Fighting liverflukes with food safety education. Science. 2011;331:282-3.

32. Oh JK, Lim MK, Yun EH, Cho H, Park EY, Choi MH, et al. Control of clonorchiasis in Korea: effectiveness of health education for community leaders and individuals in an endemic area. Trop Med Int Health. 2014;19:1096-104.

33. Huang Y, Huang D, Geng Y, Fang S, Yang F, Wu C, et al. An integrated control strategy takes Clonorchis sinensis under control in an endemic area in South China. Vector Borne Zoonotic Dis. 2017;17:791-8.

34. Tang ZL, Huang Y, Yu XB. Current status and perspectives of Clonorchis sinensis and clonorchiasis: epidemiology, pathogenesis, omics, prevention and control. Infect Dis Poverty. 2016;5:71.

35. Traub RJ, Macaranas J, Mungthin M, Leelayoova S, Cribb T, Murrell KD, et al. A new PCR-based approach indicates the range of Clonorchis sinensis now extends to central Thailand. PLoS Negl Trop Dis. 2009;3:e367.

36. Chen Y, Wen T, Lai DH, Wen YZ, Wu ZD, Yang TB, et al. Development and evaluation of loop-mediated isothermal amplification (LAMP) for rapid detection of Clonorchis sinensis from its first intermediate hosts, freshwater snails. Parasitology. 2013;140:1377-83.

37. Wang X, Chen W, Tian Y, Mao Q, Lv X, Shang M, et al. Surface display of Clonorchis sinensis enolase on Bacillus subtilis spores potentializes an oral vaccine candidate. Vaccine. 2014;32:1338-45.

\section{Figures}

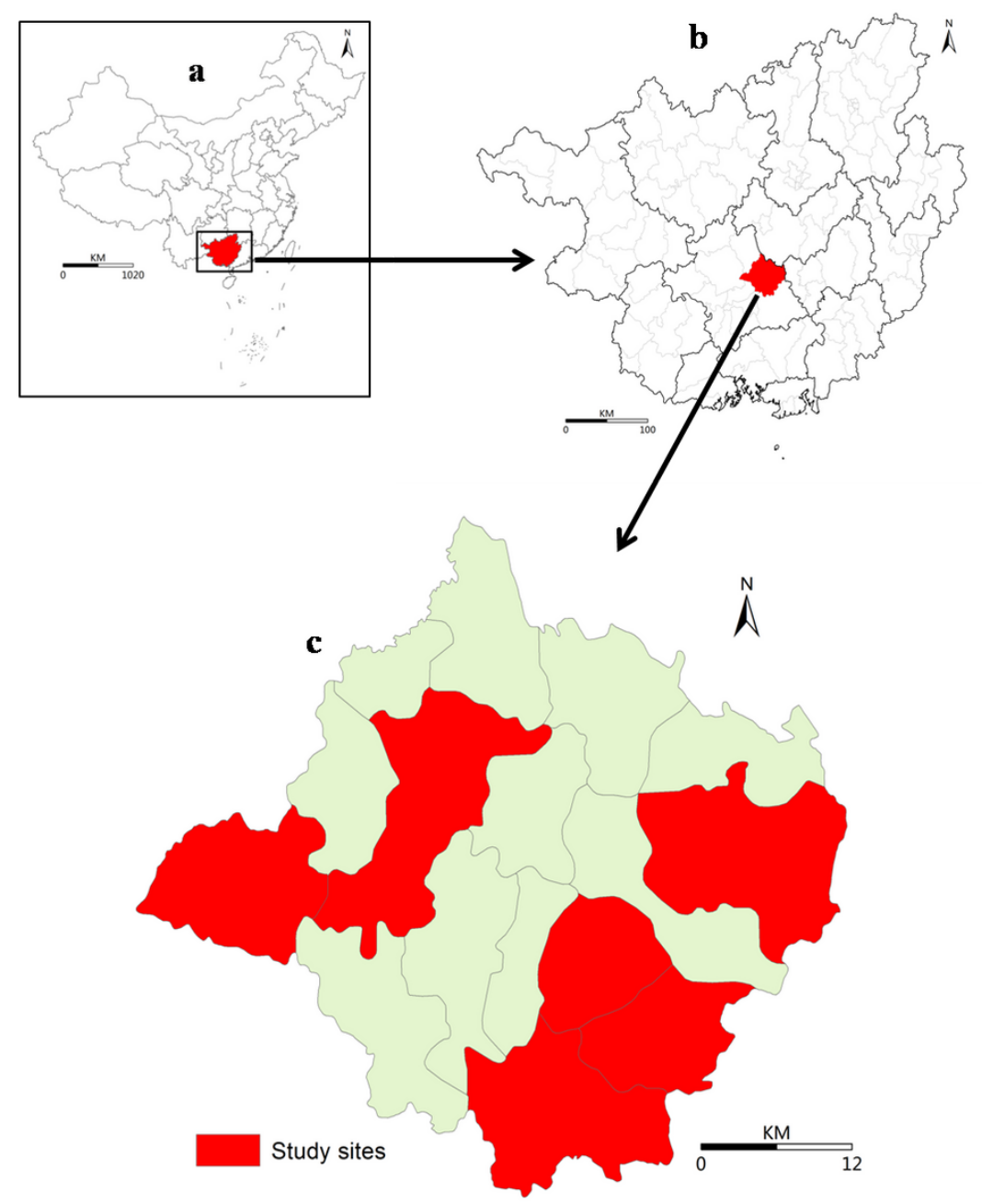

\section{Figure 1}

Geographic location of study sites in Binyang County, Guangxi Autonomous Region, China. a. Geographic location of the Guangxi Autonomous Region in China. b. Location of Binyang County in the Guangxi Autonomous Region. c. Location of the study site in Binyang County. Note: The designations employed and the presentation of the material on this map do not imply the expression of any opinion whatsoever on the part of Research Square concerning the legal 
status of any country, territory, city or area or of its authorities, or concerning the delimitation of its frontiers or boundaries. This map has been provided by the authors.
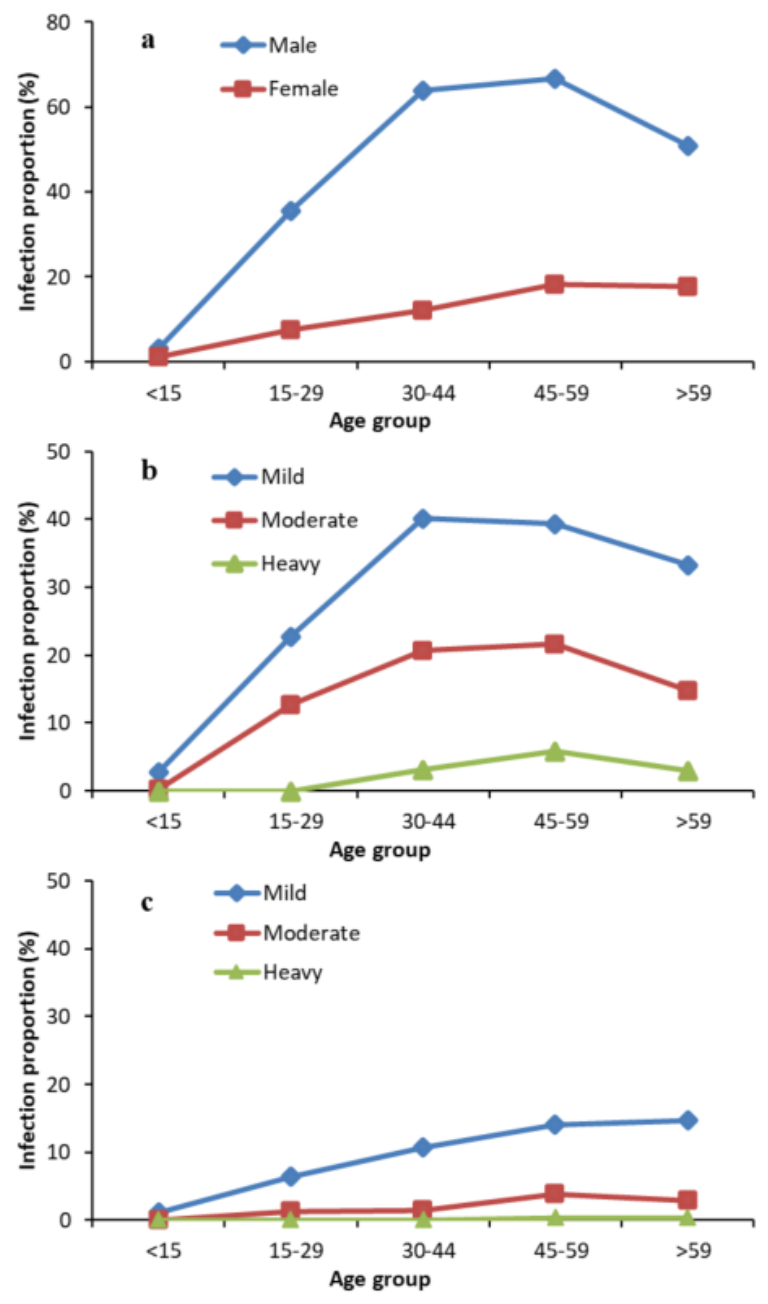

\section{Figure 2}

Infection proportion of clonorchiasis in Binyang County, Guangxi Autonomous Region, China. a. Infection proportion of clonorchiasis in different age groups by sex. b. Infection proportion of clonorchiasis for males by age group and infection intensity (mild, moderate and heavy). c. Infection proportion of clonorchiasis for females by age group and infection intensity (mild, moderate and heavy). 